\title{
Genetic Structure of the Wild Populations of the Indian Rhinoceros (Rhinoceros unicornis)
}

\author{
Samuel Zschokke*
}

(Received 12 February 2016)

\begin{abstract}
The Indian (or Greater One-horned) rhinoceros, Rhinoceros unicornis is one of only five extant rhinoceros species. In the wild it occurs exclusively in India (mainly in Assam) and in Nepal. These two populations have been completely separated for at least a few centuries. In addition, both populations experienced a bottleneck during the $20^{\text {th }}$ century. These observations suggest the questions how genetically distinct and how diverse the two populations are.

In the present study I review two molecular genetic studies on these aspects, as well as three studies, mainly based on the worldwide R. unicornis zoo population, assessing the consequences of inbreeding and outbreeding (i.e. Assam x Nepal matings) on juvenile mortality. In addition, I present the results of an analysis of the effects of inbreeding and outbreeding based on the latest studbook data.

In this analysis - in contrast to earlier studies - I no longer found a negative effect of outbreeding on offspring mortality, but still a higher mortality in primiparous offspring and still no negative effect of inbreeding on juvenile mortality.

These results suggest that outbreeding between the two populations is not as problematic as it was once suggested to be, but it also confirms that inbreeding avoidance may not be as important in the Indian rhinoceros as it is in other species.
\end{abstract}

Key words: Captive breeding, Hybridization, Inbreeding depression, Population management

\section{INTRODUCTION}

\subsection{The five rhinoceros species}

The Indian rhinoceros, Rhinoceros unicornis, is one of only five extant rhinoceros species. Two rhinoceros species live on the African continent, namely the square-lipped or white rhinoceros (Ceratotherium simum) and the hooklipped or black rhinoceros (Diceros bicornis), and three species live in Asia, the Sumatran rhinoceros (Dicerorhinus sumatrensis), the Javan or lesser one-horned rhinoceros ( $R$. sondaicus), and the Indian or greater one-horned rhinoceros $(R$. unicornis).
In both African rhinoceros species, protection efforts were rather successful - despite the loss of some sub-species - and both species have recovered to large populations sizes of c 20000 individuals (square-lipped rhinoceros) and c 5000 individuals (hooked-lipped rhinoceros) in 2012 (Knight 2013). In Asia, conservation efforts were not equally successful everywhere. Habitat loss and poaching resulted in a strong decline of the Sumatran and the Javan rhinoceros over the last decades, leading to the gloomy situation in 2013 with probably fewer than 100 Sumatran rhinoceros (International Rhino Foundation 2015b) and only about 60 Javan

\footnotetext{
* Department of Environmental Sciences, Section of Conservation Biology, University of Basel, St. Johanns-Vorstadt 10, CH4056 Basel, Switzerland, Email: samuel.zschokke@unibas.ch
} 
rhinoceros alive (Haryono et al. 2015). The only Asian rhinoceros species that is not critically endangered is the Indian rhinoceros (IUCN 2008). Thanks to the protection efforts of India and Nepal, its total population in 2015 stood at c 3500 individuals (Talukdar 2015), with a good outlook for a further increase over the next years (International Rhino Foundation 2015a), also because of to the re-established Indian rhinoceros populations in the protected areas of Suklaphanta, Dudhwa, Bardia and Manas.

\subsection{Population history of the Indian rhinoceros}

Some five hundred years ago, probably several hundred thousand Indian rhinoceros lived in the river basins of the Indus, the Ganges and the Brahmaputra rivers along the Southern edge of the Himalayas (Blanford 1891; Laurie 1979; Dinerstein \& McCracken 1990). Since the $19^{\text {th }}$ century, land clearing and hunting reduced their number to a few hundred individuals early in the $20^{\text {th }}$ century. Protection efforts have since helped the species to recover and today, Indian rhinoceros occur in ten National Parks and Wildlife sanctuaries in Nepal and in the states of Uttar Pradesh, West Bengal and Assam in India (Table $1)$.
In 1908, when rhinoceros hunting was banned, only few individuals were left in the area of today's Kaziranga National Park in Assam. The exact number is unknown, but some reports suggest that there were as few as 12 animals left (Ryhiner 1961; Ullrich 1972; Laurie et al. 1983). Since then, the population recovered, at first slowly then at a much higher rate (Fig. 1). In 2015, the population estimate for the Kaziranga National Park stood at 2401 individuals, with another 222 individuals in other protected areas in Assam, and

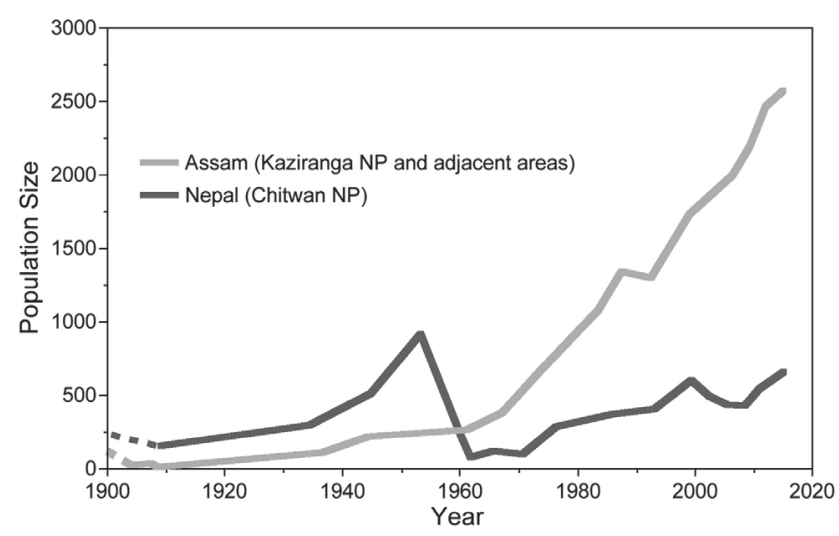

Fig 1. Reported population development of the Indian rhinoceros in Assam and in Nepal since c 1900. Both populations have been reported to have gone through a population bottleneck, the Assam population in 1908 and the Nepal population in 1962.

Table 1. Protected areas with Indian rhinoceros in India and Nepal, ordered from West to East. (NP = National Park, WLR $=$ Wildlife reserve, WLS $=$ Wildlife sanctuary). Population sizes are taken from Talukdar (2015)

\begin{tabular}{|lcl|}
\hline Protected area & Population & Remarks \\
\hline Suklaphanta WLR (Nepal) & 8 & reintroduced from Chitwan \\
Dudhwa NP (Uttar Pradesh) & 30 & reintroduced from Kaziranga and Chitwan \\
Bardia NP (Nepal) & 29 & reintroduced from Chitwan \\
Chitwan NP (Nepal) & 608 & (including the adjacent Parsa WLR) \\
Gorumara NP (West Bengal) & 50 & \\
Jaldapara NP (West Bengal) & 186 & \\
Manas NP (Assam) & 30 & \\
Pabitora WLS (Assam) & 92 & extinct 1996, reintroduced from Kaziranga \& Pabitora \\
Orang NP (Assam) & 100 & \\
Laokhowa WLS (Assam) & 0 & \\
Kaziranga NP (Assam) & 2401 & \\
TOTAL & 3534 & \\
\hline
\end{tabular}


236 individuals in protected areas in the neighbouring state of West Bengal (Talukdar 2015).

In Nepal, the population was less affected by hunting and was doing relatively well into the 1950s when land clearing and poaching reduced the population to about $60-80$ individuals in the early 1960s (Laurie 1979). The Nepal population subsequently recovered to reach about 600 individuals in 1999. But when the civil war broke out in Nepal, the protection of the rhinoceros diminished and consequently, the population was reduced to about 400 animals in 2008 (Poudyal et al. 2009; Talukdar 2009). Luckily, the situation has become more stable since, which allowed a recovery to more than 600 animals in 2015 (Talukdar 2015).

To summarize, we now have two large, isolated populations of Indian rhinoceros, one in Assam and one in Nepal, and both populations went through a bottleneck during the $20^{\text {th }}$ century. The long separation of the two populations could be expected to lead to a genetic differentiation between the two populations, and the bottlenecks could be expected to lead to a low genetic diversity in the two populations.

\section{Evolutionarily Significant Unit (ESU)}

Based on the history of the two populations, it is therefore reasonable to ask, whether they should be treated as separate 'Evolutionarily Significant Units' (ESU, i.e. populations of organisms that are considered distinct for purposes of conservation), and that they should therefore not be interbred, neither in the wild (e.g. in reintroduction programs), nor in captivity, i.e. in zoological gardens. Criteria for ESU often include the following (depending to some degree whom you ask) (Moritz 1994; Moritz 2002):

1. Current geographic separation

2. Genetic differentiation at neutral markers
3. Locally adapted phenotypic traits caused by differences in selection

Based on the first criteria, the two populations are separate ESUs because they are clearly geographically separated from each other. While unfortunately no data is available on locally adapted phenotypic traits (third criteria), the genetic differentiation has been analyzed some years ago and is summarized in the following section.

\subsection{Genetic differentiation between populations}

To analyze the genetic differentiation between and the genetic variability within the two large remaining populations of the Indian rhinoceros in Assam and Nepal, DNA samples from 47 individuals were collected and then analyzed with mitochondrial and microsatellite markers (Zschokke et al., 2011). In these samples, 10 different mitochondrial D-loop haplotypes were identified, of which 4 were specific to the Assam population ( 10 sequences examined) and 6 specific to the Nepal population (19 sequences), with no overlap between the two populations. Similarly, the analysis of 8 microsatellite loci revealed a genetic differentiation $\left(\mathrm{F}_{\mathrm{ST}}=0.20 ; \mathrm{p}<0.001\right)$ between the Assam and Nepal populations that

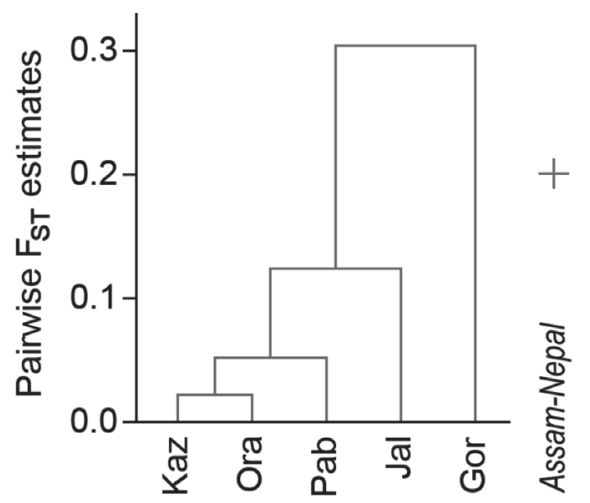

Fig. 2. UPGMA tree of the genetic distances $\left(\mathrm{F}_{\mathrm{ST}}\right.$, based on microsatellite data) between the populations in protected areas in West Bengal and Assam (based on data by Das et al. 2015). To the right: genetic distance between the Assam and the Nepal populations (Zschokke et al. 2010). (Kaz = Kaziranga NP, Ora = Orang NP, Pab = Pabitora WLS, Jal = Jaldapara NP, Gor = Gorumara NP). 
was sufficiently clear to assign each individual to its origin with high confidence (and would therefore also allow to determine the origin of confiscated material such as rhinoceros horns).

In a second study, Das et al. (2015) employed nine microsatellite markers to analyze 238 noninvasively sampled individual rhinoceros to assess the genetic diversity and population genetic structure of the Indian rhinoceros populations in India, namely in five protected areas in Assam (Kaziranga NP, Orang NP and Pabitora WLS) and West Bengal (Jaldapara NP and Gorumara NP). They found a significant level of genetic differentiation among the protected areas of Assam and West Bengal. In particular, they found a strong differentiation between the Gorumara National Park and the other protected areas $\left(F_{\mathrm{ST}} \geq 0.25 ; \mathrm{p}<0.001\right.$; Fig. 2). Interestingly, the $\mathrm{F}_{\mathrm{ST}}$ values between the Gorumara population and the other sampled populations were all larger than the $\mathrm{F}_{\mathrm{ST}}$ value of 0.20 between the Assam population and the Nepal population found by Zschokke et al. (2011).

\subsection{Genetic variability within populations}

The within-population genetic variability differed among the analyzed populations (Fig. 3). The Kaziranga population showed the highest allelic richness as well as the highest observed and expected heterozygosities. On the other hand, the Nepal population had a rather low genetic diversity. The lowest diversity was observed in the Gorumara population.

The high genetic diversity observed in the Kaziranga population is not consistent with the reported severe bottleneck early in the $20^{\text {th }}$ century. This suggests that the bottleneck was not as severe as previously thought or that individuals from other areas in Assam, or even from West Bengal, have moved into the Kaziranga area since the bottleneck (Bist 1994). On the other hand, the relatively low diversity observed in the Nepal population does not match the reported high
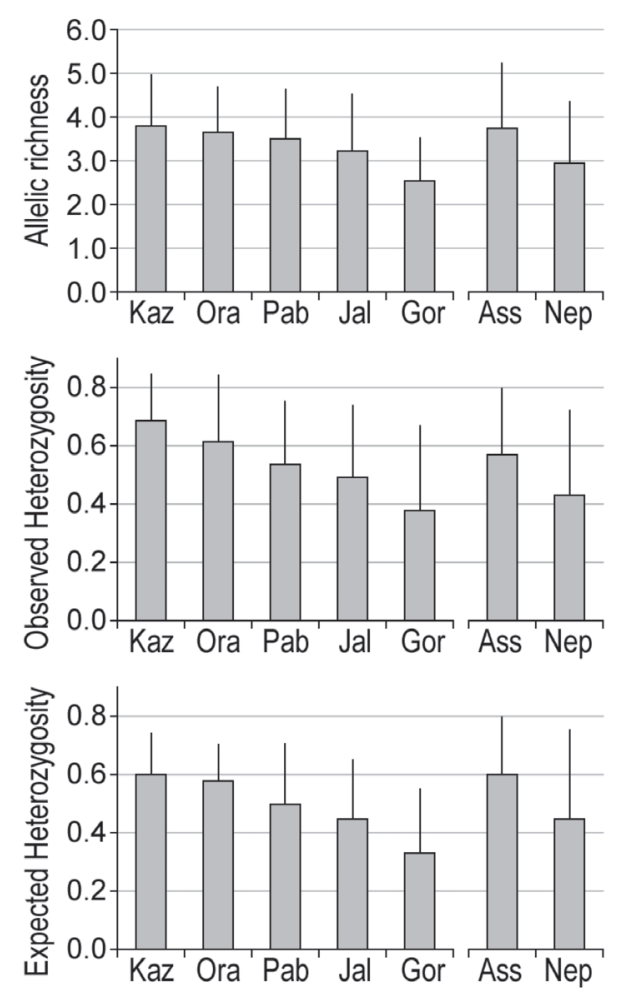

Fig. 3. Comparison of the allelic richness $\left(A_{r}\right)$, the observed heterozygosity $\left(\mathrm{H}_{\mathrm{O}}\right)$ and the expected heterozygosity $\left(\mathrm{H}_{\mathrm{E}}\right)$ among the Indian rhinoceros populations five protected areas in India (based on data by Das et al. 2015, but considering only the eight microsatellite loci which were also used in the study by Zschokke et al. 2011), as well as in populations in Assam (Ass, mainly from Kaziranga NP) and Nepal (Nep; based on data by Zschokke et al 2011).

heterozygosity based on protein electrophoresis (Dinerstein \& McCracken 1990).

\section{Should the Assam and the Nepal POPULATION BE TREATED AS SEPARATE ESUS?}

The facts that the two populations are geographically separated and that they are genetically distinct suggest that they are separate ESUs and that they should therefore not be interbred, neither in the captive population nor in reintroduction programs. However, before the decision to treat the two populations as separate ESUs is made and implemented, it is important to evaluate its possible consequences. Treating the two populations as separate ESUs would have the 
advantage that there would be no outbred (Assam $\mathrm{x}$ Nepal) individuals. On the other hand there would be more inbreeding, since all matings would have to be within the populations, which limits the choice of mating partners.

It is therefore important to evaluate whether the consequences of outbreeding or those of inbreeding are worse. There is no general answer for that question, since the consequences of outbreeding vary with the genetic differentiation between the populations or sub-species, and also because consequences of inbreeding vary greatly among species (Krummenacher, 2006; Boakes et al., 2007). Accordingly, specific analyses concerning the consequences of outbreeding and inbreeding in the Indian rhinoceros are needed.

Since both outbreeding and inbreeding can lead to an increased juvenile mortality, analyses of juvenile mortality, e.g. based on the studbook of the zoo population, can give important indications on the consequences of outbreeding and inbreeding. While juvenile mortality can be a good indicator of some consequences of outbreeding and inbreeding, it should be noted that other consequences of outbreeding (e.g. maladaptation of offspring to different local conditions) or of inbreeding (e.g. reduced adaptability due to reduced genetic diversity) are ignored when focussing solely on juvenile mortality.

\section{Consequences of outbreeding AND INBREEDING BASED ON STUDBOOK ANALYSES}

Indian rhinoceros have been kept regularly in captivity since the 19th century (Rookmaaker 1998), and the first successfully captive-bred Indian rhinoceros was born 1956 at Basel Zoo (Lang 1956). Basel Zoo also initiated the international studbook for the Indian rhinoceros (Lang et al. 1977). Studbooks dynamically document the pedigree and the demographic history of each individual in a population of a species (Association of Zoos \& Aquariums 2014). Studbook analyses are statistical analyses to find patterns in the data and are made based on the assumption, that wild caught animals are unrelated to each other. Statistical analyses require a large sample size to be reliable, and due to their nature have to ignore individual histories, e.g., when analysing juvenile mortality, the exact cause of death of the individuals is ignored. Nevertheless, when the sample size is large enough, the consequences of, e.g., inbreeding on juvenile mortality can be clearly demonstrated in many species (Boakes et al. 2007). In the following, I review the three published studbook analyses concerning factors affecting juvenile mortality in the Indian rhinoceros published between 1995 and 2007 (in all studies summarised here, juvenile death was defined as dying before reaching the age of 6 months).

The first studbook analysis of the Indian rhinoceros was performed by Baur and Studer (1995). This analysis was based on the 1991 studbook (Tobler 1991), which listed 101 zoo births that could be evaluated (i.e. of which sufficient information was known). The authors used separate $\chi^{2}$ analyses to determine whether any of the four analysed factors (inbreeding [yes/ no], parity [primiparous/multiparous], inbreeding mother [yes/no], origin mother [wild-born / zooborn]) influenced the juvenile mortality of the offspring (Table 2). Due to the low sample size, only parity was found to be significant, indicating a higher mortality $(38.5 \%)$ of the primiparous (first-born) offspring compared to offspring of multiparous females $(10.4 \%)$.

The second analysis (Zschokke \& Baur, 2002) focused on the possible consequences of outbreeding and was based on the then latest studbook (Hlavacek \& Studer 2002). This studbook listed 169 zoo births, of which 12 were outbred, i.e. derived from Assam x Nepal matings. The other 157 births were non-outbred (all Assam $\mathrm{x}$ Assam). The authors used a multiple logistic 
Table 2. Factors whose influence on juvenile mortality was analysed in the study by Baur and Studer (1995). Overall juvenile mortality was $18.3 \%$. Significant factors are emphasized in bold

\begin{tabular}{|lllrlrr|}
\hline Factor & $\mathrm{p}$ & & \multicolumn{3}{c|}{ ratio and percentage of non-surviving offspring } \\
\hline Inbreeding & 0.133 & inbred: & $2 / 24=8.3 \%$ & non-inbred: & $17 / 77=22.1 \%$ \\
Parity & $\mathbf{0 . 0 0 1}$ & primiparous: & $10 / 26=38.5 \%$ & multiparous: & $7 / 67=10.4 \%$ \\
Inbreeding mother & 0.673 & inbred: & $3 / 13=23.1 \%$ & non-inbred: & $16 / 88=18.2 \%$ \\
Origin mother & 0.160 & wild-born: & $5 / 41=12.2 \%$ & zoo-born: & $14 / 60=23.3 \%$ \\
\hline
\end{tabular}

regression to analyse factors affecting juvenile mortality. Apart from confirming that primiparous offspring suffer from an increased mortality, the analysis suggested that outbred individuals have a higher mortality than non-outbred ones, that inbred individuals have a lower(!) mortality than non-inbred ones, and that offspring mortality increases with the age of the mother and decreases with the age of the father (Table 3). Based on these results, the authors suggested: "Until more is known about the genetic relationship between the two populations, it would therefore be advisable to discontinue matings between individuals from the two populations and to encourage matings among individuals from the Nepal population". Unfortunately, most captive individuals with Nepalese origin were presents of the King of Nepal, which pretty much ruled out that these animals could be transferred to zoos in other countries. In addition, of the 15 individuals with Nepalese origins only 4 were males (3 of which were in the USA, and 1 in India), which made matings among Nepalese individuals even trickier.

A few years later, Pluháček (2007) made another analysis, which, in addition to the studbook data from the 2003 edition of the studbook (Hlavacek et al. 2003), included 22 births from the Dudhwa National Park (Uttar Pradesh, India), to where seven Indian rhinoceros had been reintroduced from Pabitora WLS (Assam, India) and Chitwan NP (Nepal) (Sinha et al. 2004). For their study, Pluháček et al. used a generalized linear model to analyze which factors affect juvenile mortality. Their analysis again confirmed that primiparous offspring have an increased mortality, and it also confirmed that offspring mortality increases with age of the mother (Table 4). In contrast to the previous analysis, they could neither confirm that inbred offspring have a reduced mortality nor that outbred offspring have an increased mortality. However, the interpretation of their result on the influence of outbreeding was unfortunately not entirely correct. A non-

Table 3. Factors whose influence on juvenile mortality was analysed in the study by Zschokke and Baur (2002). Overall juvenile mortality was $20.0 \%$. Factors found to be significant are emphasized in bold

\begin{tabular}{|c|c|c|c|c|c|c|c|}
\hline \multirow{2}{*}{$\begin{array}{l}\text { Factor } \\
\text { Inbreeding }\end{array}$} & \multirow{2}{*}{$\begin{array}{l}\mathrm{p} \\
\mathbf{0 . 0 1 8}\end{array}$} & \multicolumn{6}{|c|}{ ratio and percentage of non-surviving offspring } \\
\hline & & inbred: & $6 / 44$ & $=13.6 \%$ & non-inbred: & $28 / 125$ & $=22.4 \%$ \\
\hline Outbreeding & 0.003 & outbred: & $5 / 12$ & $=41.7 \%$ & non-outbred: & $29 / 157$ & $=18.5 \%$ \\
\hline Parity & 0.015 & primiparous & $14 / 44$ & $=31.8 \%$ & multiparous: & $19 / 118$ & $=16.1 \%$ \\
\hline Age father & 0.001 & \multicolumn{6}{|c|}{ mortality decreasing with age of father } \\
\hline Age mother & 0.002 & \multicolumn{6}{|c|}{ mortality increasing with age of mother } \\
\hline Origin mother & 0.034 & wild-born: & $10 / 58$ & $=17.2 \%$ & zoo-born: & $24 / 111$ & $=21.6 \%$ \\
\hline Zoo & 0.024 & & & & & & \\
\hline Sex & 0.643 & male: & $17 / 98$ & $=17.3 \%$ & female: & $16 / 70$ & $=22.9 \%$ \\
\hline
\end{tabular}


Table 4. Factors whose influence on juvenile mortality was analysed in the study by Pluháček et al. (2007). Significant factors are emphasized in bold, those denoting trends $(\mathrm{p}<0.1)$ are emphasized in italics.

\begin{tabular}{|c|c|c|c|c|c|c|c|}
\hline Factor & $\mathrm{p}$ & \multicolumn{6}{|c|}{ ratio and percentage of non-surviving offspring } \\
\hline Inbreeding & 0.518 & & & & & & \\
\hline Outbreeding & 0.065 & outbred: & $11 / 32$ & $=34.4 \%$ & non-outbred: & $37 / 171$ & $=21.6 \%$ \\
\hline Parity & 0.004 & primiparous: & $21 / 62$ & $=33.8 \%$ & multiparous: & $27 / 141$ & $=19.1 \%$ \\
\hline Age father & 0.128 & & & & & & \\
\hline Age mother & 0.021 & \multicolumn{6}{|c|}{ mortality increasing with age of mother } \\
\hline Origin mother & 0.129 & & & & & & \\
\hline $\operatorname{Sex}$ & 0.095 & & & & & & \\
\hline Captivity & 0.219 & zoo born: & $42 / 181$ & $=23.2 \%$ & wild born: & $6 / 22$ & $=27.3 \%$ \\
\hline
\end{tabular}

significant $p$-value for any factor does not mean that this factor plays no role, as Pluhacek et al. have interpreted it, it rather means that its role could not be proven. Particularly, if a p-value is less than 0.1 , as it was the case for the factor 'outbreeding' ( $p=0.065)$ in their analysis, it is customary to interpret it as an indication that the factor in question could play a role. Nevertheless, despite that shortcoming, Pluháček et al. correctly identified a problem in the dataset used in the analysis by Zschokke and Baur (2002), namely that the factors parity and outbreeding were not independent in their dataset, since half of the outbred offspring were also primiparous, a much larger proportion than in the non-outbred offspring.

\section{NeW STUdBoOK ANALYSIS BASED ON THE LATEST STUDBOOK DATA}

The previous studbook analyses of the Indian rhinoceros did not conclusively answer the question, to what extent inbreeding and outbreeding influence juvenile mortality. Spurred by the invitation to deliver a lecture on the 'Genetic Structure of the Wild Populations of the Indian rhinoceros', the author of the present paper decided to repeat the analysis by Zschokke \& Baur (2002) with the latest studbook data (von Houwald, 2015). This studbook edition listed 326 births, of which 100 were outbred and 226 were non-outbred. Of the non-outbred births, 221 were of Assam origin, and 5 of Nepal origin. A logistic regression calculated with likelihood ratios was used to determine the influence of inbreeding [yes/no], outbreeding [yes/no], parity [primiparous/multiparous], age father, age mother, origin of mother [zoo/wild], zoo and sex [male/ female]. This model was stepwise reduced by eliminating factors with $p>0.5$. The regression was calculated using JMP vers. 3.2.2 for Macintosh (SAS Institute 1997).

The results of this analysis (again) showed that juvenile mortality was strongly influenced by parity, and that it decreased with age of father and increased with age of mother. On the other hand, neither inbreeding nor outbreeding nor sex were found to have a significant influence on juvenile mortality (Table 5).

\section{Discussion OF NEW RESULTS}

It is little surprising that primiparous offspring have an increased mortality, as this is quite common in many mammalian species (Debyser, 1995; Ibañez et al., 2013).

Probably of greater interest is the observation that outbreeding does indeed not seem to be problematic concerning juvenile mortality. However, it remains unknown whether outbred individuals may suffer from some maladaptations to different local conditions in the wild. In the zoo population, the number of outbred zoo-births 
Table 5. Results of the studbook analysis based on the studbook data 2015 . Overall juvenile mortality was $21.5 \%$. The factor 'origin of mother' was eliminated during stepwise reduction. Significant factors are emphasized in bold, those denoting trends $(\mathrm{p}<0.1)$ are emphasized in italics.

\begin{tabular}{|lllclll|}
\hline Factor & $\mathrm{p}$ & & \multicolumn{4}{c|}{ Ratio and percentage of non-surviving offspring } \\
\hline Inbreeding & 0.099 & inbred: & $17 / 94=18.1 \%$ & non-inbred: & $53 / 232=22.8 \%$ \\
Outbreeding & 0.493 & outbred: & $24 / 100=24.0 \%$ & non-outbred: & $46 / 226=20.4 \%$ \\
Parity & $\mathbf{0 . 0 0 1}$ & primiparous: & $30 / 87=34.5 \%$ & multiparous: & $37 / 229=16.2 \%$ \\
Age father & $\mathbf{0 . 0 4 8}$ & mortality decreasing with age of father & & \\
Age mother & $\mathbf{0 . 0 1 9}$ & mortality increasing with age of mother & & \\
Zoo & $\mathbf{0 . 0 0 2}$ & & & & & \\
Sex & 0.194 & male: & $39 / 179=21.8 \%$ & female: & $31 / 146=21.2 \%$ \\
\hline
\end{tabular}

increased sharply after 2002 (Fig. 4); between 2000 and $2014,88(56.4 \%)$ of the 156 zoo-born Indian rhinoceros were outbred. It is therefore quite fortunate that outbreeding does indeed not appear to be problematic; otherwise the zoo population would now face a problem with its large proportion of outbred individuals.

It is also interesting to note that there is no inbreeding depression concerning juvenile survival in the Indian rhinoceros; in fact, the results of the present study even suggest that inbred offspring could have a lower mortality than noninbred offspring. The reasons for this quite unusual correlation are unclear. Zschokke and Baur (2002) had suggested that the severe bottleneck reported

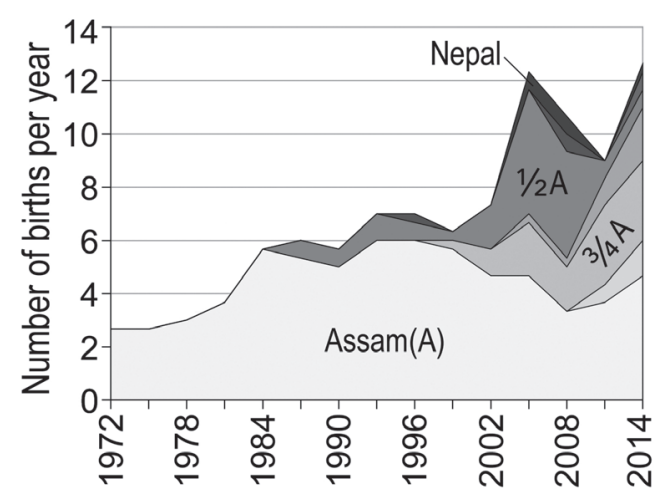

Fig. 4. Development of the number of zoo-births of Indian rhinoceros averaged over 3 years. Shaded areas indicate the genetic origin of the new-borns: Assam(A) $=100 \%$ Assam; $3 / 4 \mathrm{~A}=75 \%$ Assam \& 25\% Nepal; $1 / 2 \mathrm{~A}=50 \%$ Assam \& 50\% Nepal; Nepal $=100 \%$ Nepal, intermediate areas indicate intermediate fractions. for the Kaziranga population, from which most of the captive individuals descend, had lead to a purging of the lethal alleles, which cause the inbreeding depression. However, thanks to the molecular genetics studies (see above) we now know that the bottleneck was not as severe as previously thought. So after all it is not clear, why inbreeding does not increase juvenile mortality in the Indian rhinoceros, as it does in many other species (Krummenacher 2006; Boakes et al., 2007).

Another fascinating aspect (though not really connected to population genetics) is the observation that offspring mortality was found to decrease with age of the father. In evolutionary terms, this can be explained by the observation that in the wild usually only older males breed, and that there was consequently no selection pressure for young males to produce viable offspring (Zschokke \& Baur, 2002). However, it is unclear through which physiological mechanism the low age of the father could lower offspring viability.

\section{Conclusions}

Based on the latest analyses presented in this study, inbreeding does not increase juvenile mortality, and therefore inbreeding avoidance in the zoo population of the Indian rhinoceros is not as important as it is in other species. However, the preservation of the genetic diversity is 
nevertheless important, since it forms the basis for future adaptations. This is best achieved by mating individuals with a low mean kinship, but does not necessarily require interbreeding of the two populations (Ballou \& Lacy, 1995; Foose \& Wiese, 2006; Ivy \& Lacy, 2012).

When looking back at the different studbook analyses, it is interesting to see how each one had its weakness. The major weakness of the first study (Baur \& Studer, 1995) was the (at the time inevitable) low sample size. Nevertheless, this study led to the insight that inbreeding levels were becoming dangerously high and that the preservation of the genetic diversity in the zoo population of the Indian rhinoceros requires an internationally coordinated breeding programme. The second study (Zschokke \& Baur, 2002) had an overall reasonable sample size, but the dataset had the problem that parity and outbreeding were not really independent, which caused the in hindsight wrong conclusion that outbreeding was problematic. The third study (Pluháček et al., 2007), had the weakness that the conclusion "outbreeding did not play any role in infant mortality" was drawn from results which did not support this conclusion. However, with the present study it could be shown that this conclusion was not so wrong after all.

\section{ACKNOWLedgments}

I am very grateful to Partha Majumder and his colleagues for inviting me to the symposium of the Indian National Science Academy on "The Indian heritage: a genomic view", which gave me the impetus to re-analyze the studbook data of the Indian rhinoceros. This study would not have been possible without the support of Basel Zoo, namely of its director, Oliver Pagan and the studbook keeper of the Indian rhinoceros, Friederike von Houwald, who made the latest studbook data available to me. I am furthermore grateful to Bruno Baur, and to my family for all their support. Last but not least I would also like to thank the Rhino
Resource Center (http://www.rhinoresource center.com) for making so much information on the rhinoceroses available.

\section{BiBLIOGRAPHY}

Association of Zoos \& Aquariums. Studbooks. https:// www.aza.org/studbooks, 2014, accessed on 26-Dec2015.

Ballou, J D and Lacy, R C. Identifying genetically important individuals for management of genetic variation in pedigreed populations, in Ballou J D, Gilpin M and Foose T J (ed), Population management for survival and recovery: analytical methods and strategies in small population conservation, Columbia University Press, New York NY, 1995, pp.76-111.

Baur, B and Studer, P. Inbreeding in captive Indian rhinoceros. International Zoo Yearbook, 34 (1995): 205-211.

Bist, S S. Population history of Great Indian Rhinoceros in North Bengal and major factors influencing the same. Zoos' Print, 9 (1994): 42-51.

Blanford, W T. The Fauna of British India, including Ceylon and Burma. Mammalia. Taylor and Francis, London, 1891.

Boakes, E H; Wang J and Amos W. An investigation of inbreeding depression and purging in captive pedigreed populations. Heredity, 98 (2007): 172-182.

Das, P K; Borthakur, U; Sarma, H K and Talukdar, B K. Population genetic assessment of extant populations of greater one-horned rhinoceros (Rhinoceros unicornis) in India. European Journal of Wildlife Research, 61 (2015): 841-851.

Debyser, I W J. Prosimian juvenile mortality in zoos and primate centers. International Journal of Primatology, 16 (1995): 889-907.

Dinerstein, E and McCracken, G F. Endangered greater onehorned rhinoceros carry high levels of genetic variation. Conservation Biology, 4 (1990): 417-422.

Foose, T J and Wiese, R J. Population management of rhinoceros in captivity. International Zoo Yearbook, 40 (2006): 174-196.

Haryono, M; Rahmat, U M; Daryan, M; Raharja, A S; Muhtarom, A; Firdaus, A Y; Rohaeti, A; Subchiyatin, I; Nugra-heni, A; Khairani, K O and Kartina. Monitoring of the Javan rhino population in Ujung Kulon National Park, Java. Pachyderm, 56 (2015): 8286. 
Hlavacek, G and Studer, P. International studbook for the Greater One-Horned Rhinoceros Rhinoceros unicornis Linné, 1758. Zoo Basel, Basel, 2002.

Hlavacek, G; Zschokke, S and Guldenschuh, G. International studbook for the Greater One-Horned or Indian Rhinoceros Rhinoceros unicornis Linné, 1758. Zoo Basel, Basel, 2003.

Ibañez, B; Moreno, E and Barbosa, A. Parity, not inbreeding, affects juvenile mortality in two captive endangered gazelles. Animal Conservation, 16 (2013): 108-117.

International Rhino Foundation. Indian Rhino Vision 2020. http://rhinos.org/where-we-work/indian-rhino-vision2020, 2015a, accessed on 27-Dec-2015.

International Rhino Foundation. Sumatran Rhino (Dicerorhinus sumatrensis). http://rhinos.org/species/ sumatran-rhino, 2015b, accessed on 30-Dec-2015.

IUCN. The IUCN Red List of Threatened Species. http:// www.iucnredlist.org, 2008, accessed on 28-Dec-2015.

Ivy, J A and Lacy, R C. A comparison of strategies for selecting breeding pairs to maximize genetic diversity retention in managed populations. Journal of Heredity, 103 (2012): 186-196.

Knight, M. African rhino group specialist report. Pachyderm, 53 (2013): 7-24.

Krummenacher, T S. Inbreeding and its consequences in threatened species. MSc thesis, Basel University, 2006.

Lang, E M. Breeding of the Indian rhinoceros at Basel zoo. Zoo Life, 11 (1956): 126-127.

Lang, E M; Leutenegger, M and Tobler, K. Indian rhinoceros births in captivity. International Zoo Yearbook, 17 (1977): 237-238.

Laurie, W A. The ecology of the Greater One-horned Rhinoceros. $\mathrm{PhD}$ thesis, University of Cambridge, 1979.

Laurie, W A; Lang, E M and Groves, C P. Rhinoceros unicornis. Mammalian Species, 211 (1983): 1-6.

Moritz C. Defining 'evolutionarily significant units' for conservation. Trends in Ecology and Evolution, 9 (1994): 373-375.

Moritz, C. Strategies to protect biological diversity and the evolutionary processes that sustain it. Systematic Biology, 51 (2002): 238-254.
Pluháček J, Sinha, S P; Bartoš, L and Š́pek, P. Parity as a major factor affecting infant mortality of highly endangered Indian rhinoceros: Evidence from zoos and Dudhwa National Park, India. Biological Conservation, 139 (2007): 457-461.

Poudyal, M; Rothley, K and Knowler, D. Ecological and economic analysis of poaching of the greater one-horned rhinoceros (Rhinoceros unicornis) in Nepal. Ecological Applications, 19(2009): 16931707.

Rookmaaker, L C. The rhinoceros in captivity. SPB Academic Publishing, Den Haag NL, 1998.

Ryhiner, P. Auf Tierfang durch die Welt. Horst Erdmann, Herrenalb D, 1961.

SAS Institute. JMP ${ }^{\circledR}$ User 's Guide. SAS Institute Inc., Cary NC, 1997.

Sinha, S P; Sawarkar, V B and Singh, S P P. Twenty years of rhino reintroduction programme in Dudhwa National Park / Tiger Reserve, Uttar Pradesh, India (19842004) - a report. Wildlife Institute of India, Dehra Dun, 2004.

Talukdar, B K. Asian rhino specialist group report. Pachyderm, 46 (2009): 14-17.

Talukdar, B K. Asian rhino specialist group report. Pachyderm, 56 (2015): 40-43.

Tobler, K. International studbook for the Great Indian Rhinoceros Rhinoceros unicornis (Linné 1758). Zoo Basel, Basel, 1991.

Ullrich, W. Kaziranga - Tierparadies am Brahmaputra. Urania Verlag, Leipzig, Jena, Berlin, 1972.

von Houwald, F. International studbook for the greater one-horned rhinoceros 2014. Zoo Basel, Basel, 2015.

Zschokke, S; Armbruster, G F J; Ursenbacher, S and Baur, B. Genetic differences between the two remaining wild populations of the endangered Indian rhinoceros (Rhinoceros unicornis). Biological Conservation, 144 (2011): 2702-2709.

Zschokke, S and Baur, B. Inbreeding, outbreeding, infant growth, and size dimorphism in captive Indian rhinoceros (Rhinoceros unicornis). Canadian Journal of Zoology, 80 (2002): 2014-2023. 